\title{
Proposed Design Philosophy for Seismic-Resistant Buildings
}

\author{
Wariyatno, N.G. ${ }^{1}$, Han, A.L. ${ }^{2}$, and Gan B.S..$^{*}$
}

\begin{abstract}
Modern seismic design and technologies have undergone tremendous developments. In modern design codes, building structures subjected to high earthquake loads are allowed to experience plastic deformations without collapsing, and the design is permitted up to the ultimate strength. According to comparative results in Japan, the number of humans injured due to earthquakes is higher than the number of deaths/missing. Likewise, the number of residential buildings that collapsed are less than the partially damaged buildings. This outcome implies that residential buildings designed based on the revised seismic standards have good earthquake resistances. It also infers that the human deaths/injury casualties were not a result of the collapsed the structure, but due to the strong vibrations originated from the earthquake, yielding in the collapse of non-structural elements such as ceilings and bookshelves. This paper presents a proposed design philosophy that attempts to implement the effect of earthquakes to non-fatal human casualties.
\end{abstract}

Keywords: Earthquake magnitude; earthquake shaking; earthquake resistant-design; human casualties; seismic design; seismic intensity.

\section{Introduction}

Japan is situated in East Asia where presently four active tectonic plates (the Pacific plate, the North American plate, the Eurasian plate, and the Philippine plate) meet at the zone called the Pacific Ring of Fire which is prone to earthquakes and volcanic eruptions. It has been reported that since the $19^{\text {th }}$ century, $20 \%$ of the earthquakes in the world with the magnitude larger than six on the Richter scale occurred in Japan. Learning from history, the technology developments in Japan for seismic-resistant building started in 1891, during the Meiji era. From long experience in developing the technologies against the failures and damages of buildings during big earthquakes, the first law enforcement on the seismic-resistant building took place in 1919. Since then, the design codes in Japan have been revised whenever larger earthquake and big casualties were encountered. The latest seismic design method allows the building structures to experience plastic deformations under large earthquakes, while remaining elastic under small or moderate earthquakes.

\footnotetext{
${ }^{1}$ Phd. Candidate, Department of Civil Engineering, Diponegoro University, Tembalang, Semarang 50275, INDONESIA

${ }_{2}^{2}$ Professor, Department of Civil Engineering, Diponegoro University, Tembalang, Semarang 50275, INDONESIA

${ }^{3}$ Professor, Department of Architecture, College of Engineering, Nihon University, Koriyama, Fukushima 963-8642, JAPAN

*Corresponding author: buntara@arch.ce.nihon-u.ac.jp
}

Note: Discussion is expected before June, $1^{\text {st }} 2018$, and will be published in the "Civil Engineering Dimension", volume 21, number 2, September 2019.

Received 26 September 2018; revised 17 December 2018; accepted 23 December 2018
The plastic deformation was anticipated to dissipate earthquake energy and to safeguard persons inside the building by preventing the structural collapse. While this design method is highly effective in protecting human lives, it does not fully account for loss of life due to non-structural impacts, such as books or dishes shelves, furniture, hanging lamps, and failures of other non-structural components due to strong shakings during the earthquakes.

There was a continuing tradition where the codes are revised merely oriented on the strength of the building structures against big earthquakes. A new seismic design approach to reduce the effect of shakings during the earthquakes is necessary for complementing of the present codes. This new seismic design approach is intended to be applied to more general structures. Such a structural design philosophy is required for modern and resilient societies. In order to achieve this goal, the rise of the construction cost becomes the main issue to resolve; however, the cost of casualties can overwhelm the cost to improve the structural performance. This paper proposes a quantitative seismic intensity level evaluation during the earthquake so that a counter measure can be resolved to reduce the shakings during the earthquakes.

\section{Statistic of Human and Building Casualties due to Earthquakes}

The Japan Meteorological Agency (JMA) has comprehensively compiled the statistic of 153 data on the locations, seismic magnitude, Japan's Seismic Intensity Level, and casualties of human and residential buildings' data from $6^{\text {th }}$ March 1996 until 18 ${ }^{\text {th }}$ June 
2018 (22 years period) due to major earthquakes in Japan [1]. Omitting the 2011 Tohoku earthquake in which the casualties of human beings and residential buildings are mostly due to the tsunami, comparisons between the number of human casualties and the collapsed of residential buildings were investigated.

Figure 1 shows the statistical data of earthquake magnitude and seismic intensity level at given locations in Japan from 153 earthquakes recorded. From Figure 1, it can be observed that the measurements of seismic intensity level are less diverge, thus reliable to be used as an evaluation tool for the new design philosophy. The circled markers show the magnitude at the epicenter of the earthquakes for the Richter scale and triangle markers show the corresponding Japan seismic intensity level (JMASIL).

Figure 2 depicts the statistical data of human casualties (deaths included missing people and injured) due to earthquakes occurring as a function of time in the Japan region. The scatter circled markers show the number of injured human casualties during the earthquakes. It can be observed that these numbers exceeded the number of death casualties (including missing) for the same occurrence of earthquake.

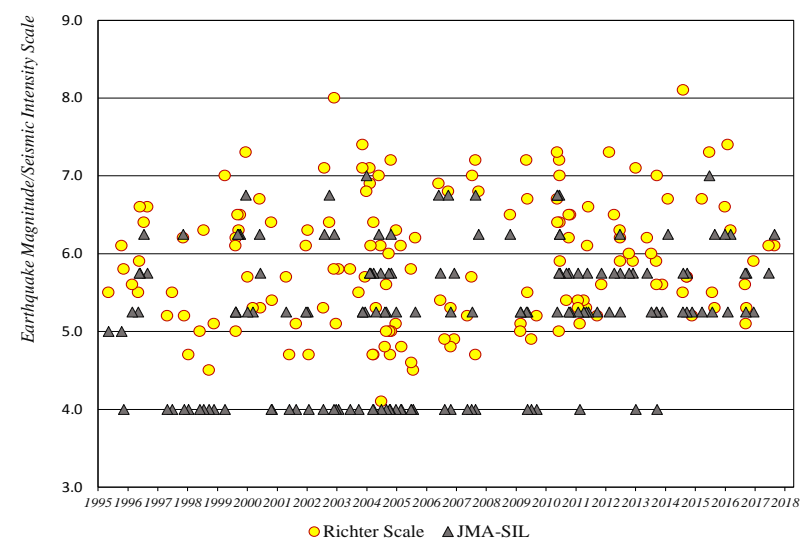

Figure 1. The Statistical Data of the Magnitude/Seismic Intensity Level of the Earthquakes.

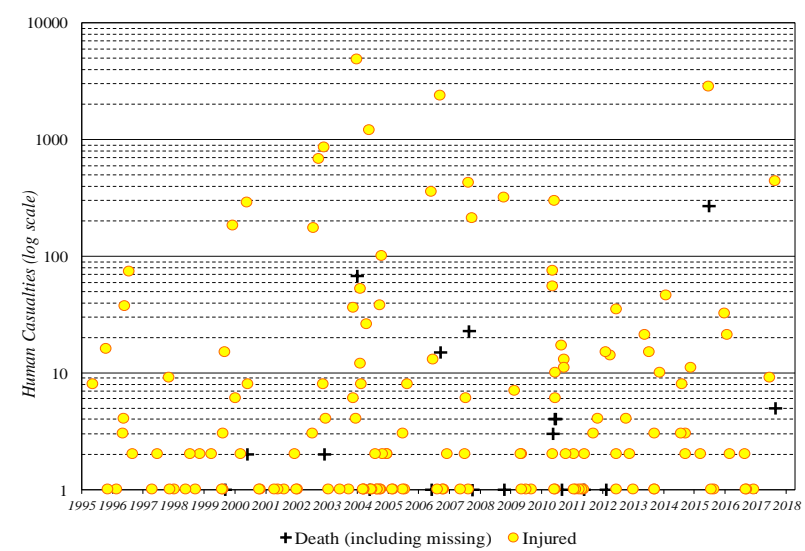

Figure 2. The Statistical Data of Human Casualties due to Earthquakes
Figure 3 depicts the statistical data of residential building casualties (collapsed or repairable partly damaged) due to earthquakes in Japan during the time span 1995 to 2018. The scattered circled markers show the number of partly damaged residential buildings during the earthquakes. The number of partially damaged buildings faintly surpasses the number of collapsed buildings in this figure denoted as triangles.

Considering the data in Figure 2 and Figure 3, in both figures the numbers of human beings injured due to the earthquakes are more dominant than the numbers of deaths/missing. Likewise, the numbers of residential collapsed buildings are less than the partly-collapsed/partly-damaged buildings. It can be concluded that the revisions on the seismic design standards over a span of 23 years constantly provided an excellent earthquake resistance for buildings to withstand even severe earthquakes. It can also be concluded that the deaths/injury of human casualties were not mainly due to the collapse of their houses, but due to the strong earthquake vibrations yielding in the damage of nonstructural elements. These components such as ceilings and bookshelves have the potential to fatally harm and even kill inhabitants. In other words, the recent design codes which are intended to protect human lives against big earthquakes do not guarantee there will be no human casualties due to earthquake shaking and vibration effects

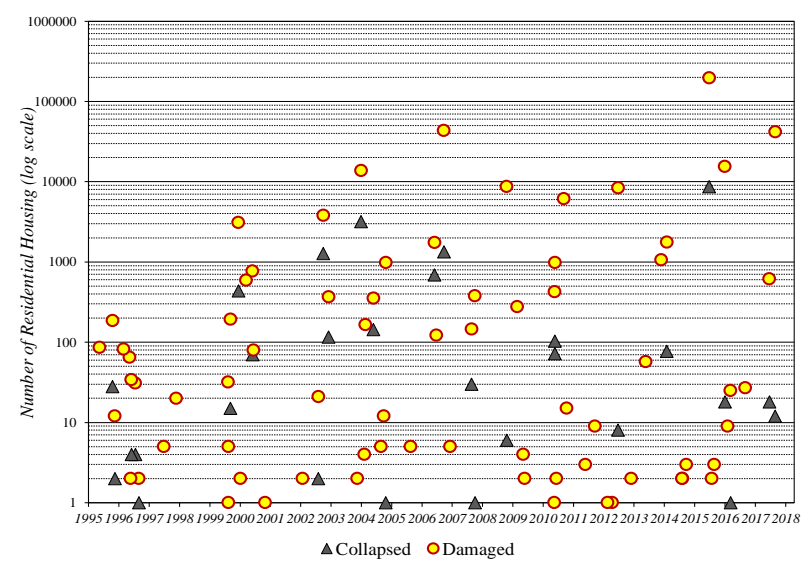

Figure 3. The Statistical Data of Residential Housing Casualties due to Earthquakes.

\section{Magnitude and Seismic Intensity Level $\left(S_{I L}\right)$}

Figure 4 illustrates the different concepts between the earthquake magnitude and seismic intensity level. The earthquake magnitude scales are used to explain the overall energy of an earthquake. These scales differ from the seismic intensity level that categorize the intensity or severity of ground shaking (quaking) caused by an earthquake at a given location. The seismic intensity levels are varying on 
the magnitude scale and are a function of depth of an earthquake epicenter, soils type, and dynamic characteristics of the building/structure.
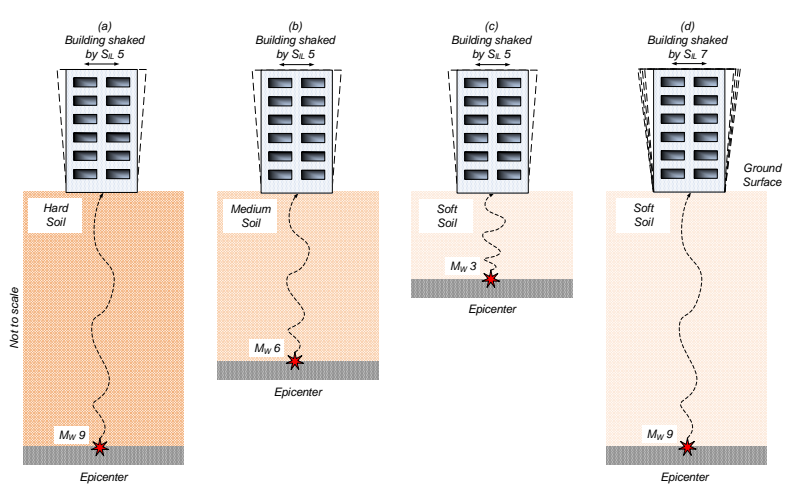

Figure 4. The Illustrations of the Earthquake Magnitude and Seismic Intensity Level

The $S_{I L}$ denotes the strength or shaking force due to an earthquake and can be associated with the Peak Ground Acceleration (PGA) and dominant period at a given location. The $S_{L}$ adopted by the Japan Meteorological Agency (JMA) [2] shown in Figure 5 is very practical because the value of $S_{L L}$ can be a quantitatively evaluated from the PGA and dominant period at a given location.

Alternately, a similar seismic intensity level, the socalled Modified Mercalli Intensity (MMI) is also used to categorize the shaking intensity effect to humans. The MMI has 12 intensity scales with descriptive illustrations and simple explanations about the effects of shaking based on qualitative perceptions [3-5].

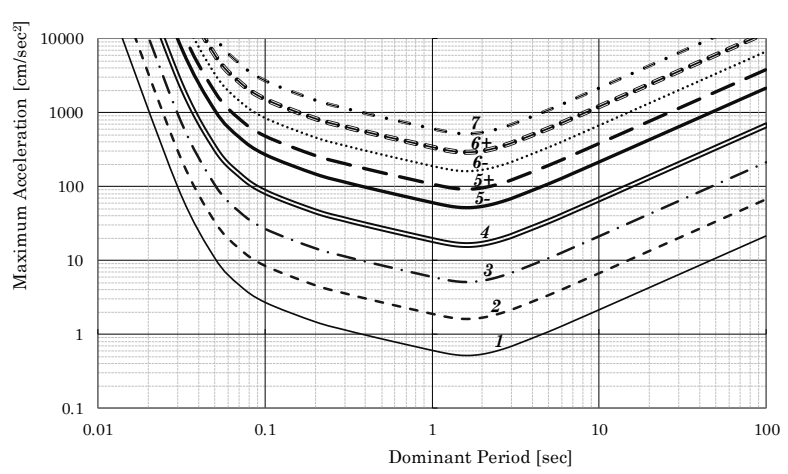

Figure 5. The Seismic Intensity Level of JMA [2]

The $S_{I L}$ of the JMA has intensity scales from one to seven, with refined categories of strong and weak between five and six scales (Table 1). The $S_{L}$ has been used in Japan to spread a quick, informative earthquake warning through the broadcasting television to the entire country. The main purpose of this $S_{I L}$ is intended for disaster mitigation of Japanese people when the country is struck by an earthquake.
Table 1. Seismic Intensity Level Impact [2]

\begin{tabular}{cl} 
Scale & Human perception and reaction \\
\hline 0 & $\begin{array}{l}\text { Imperceptible to people, but recorded by } \\
\text { seismometers }\end{array}$ \\
& $\begin{array}{l}\text { Felt slightly by some people in quiet situations in } \\
\text { buildings }\end{array}$ \\
2 & $\begin{array}{l}\text { Felt slightly by the many people in quiet } \\
\text { situations in buildings, some sleeping people } \\
\text { maybe awoken }\end{array}$ \\
3 & Felt by the majority of building inhabitants, and \\
awoken a large number of sleeping people. Felt \\
by some people walking
\end{tabular}

As an illustrative example, two earthquakes shown in Figure 6 which occurred in different locations in Japan in the same year are selected. The Miyagi earthquake occurred on 26 May 2003, had a magnitude 7.0 at the epicenter.
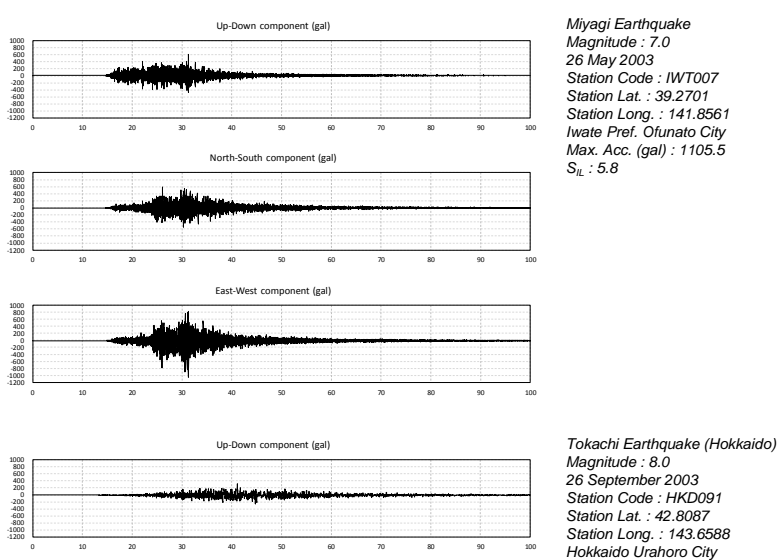
Magnitude : 8.0 26 September 2003 Station Code : HKDO91
Station Lat. : 42.8087 Statition Lat. : 42.8087 Hokkaido Urahoro City

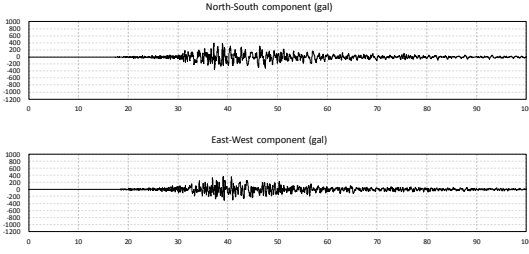
Max. Acc. (gal) : 454.8
$S_{U}: 5.8$

Figure 6. Relationship between Acceleration, Period and $S_{I L}$ of JMA [2]

In the Ofunato city of Iwate prefecture, the earthquake was recorded to have the PGA of 1105.5 gals with $S_{I L}=5.8$. In the same year, the Tokachi earthquake occurred on 26 September 2003 with magnitude 8.0. At that time, in the Urahoro city of Hokkaido, the earthquake was recorded to have the PGA of only 454.8 gals with the same $S_{L}=5.8$. 
Thus, even though both earthquakes have a different magnitude of earthquakes and PGAs, they have the same value of $S_{I L}=5.8$. The distance, soil conditions, and depth of the epicenter of the earthquakes are the main reasons behind these phenomena. Figure 6 also shows two different characteristics of seismic waves, the soil condition in Ofunato city has the dominant period about $0.075 \mathrm{sec}$ (hard soil) while the soil condition in Urahoro city has the dominant period about $0.12 \mathrm{sec}$ (medium soil). If both earthquakes' PGA and dominant period are plotted in Fig. 5, the same $S_{I L}=5.8$ can be obtained.

The comparisons imply that the location with large PGA and earthquake magnitude do not have correlations with the seismic intensity $S_{I L}$, the level of shaking. The relationships either between the PGA and $S_{I L}$ or between the earthquake magnitude and $S_{I L}$ are not inherent. However, the shaking level of an earthquake which can be expressed by the $S_{I L}$ number is affected by the distance and depth from the epicenter of the earthquake and PGA. The shaking level $S_{L}$ also can be used to determine the human and building casualties during the occurrences of big earthquakes.

Because the $S_{I L}$ of JMA can be evaluated quantitatively, it is an important evaluation tool for determining the efficiency by reducing the seismic intensity at a given location yet be used in current seismic design method to decrease the number of human casualties even if the houses are designed not to collapse.

\section{Implementation of Quantitative $S_{I L}$ Evaluation in the Design Code}

Figure 7 shows the illustrations of quantitative determination scheme of $S_{L L}$ of a residential building example. Suppose the building has passed the seismic design stage, after then the evaluation of shaking level can be conducted. Based on the soil conditions and the dynamic characteristics of the building, the selected response spectrum for design is used to generate the seismic wave at the location where the building will be built. Then, by using the seismic wave as the input ground motion, a time history analysis is performed. From the results of the analysis, the time history accelerations at different floors of the building are analyzed by using the Fast Fourier Transform method to determine the dominant period of each floor and the maximum response acceleration. The dominant periods and maximum response accelerations of the floors are plotted into the JMA Seismic Intensity Level to determine the shaking levels of the floors.
When there is one floor with a $S_{I L}$ higher than the allowance, the design should be revised to incorporate this insufficiency. The limitation or allowed seismic intensity level has to be set in the seismic design codes in order to reduce human casualties due to the shaking during the big earthquakes.

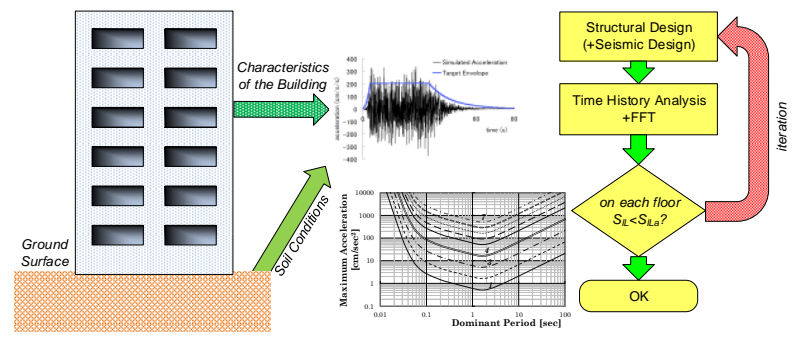

Figure 7. Implementation of Quantitative $S_{L L}$ for Seismicresistant Design of Building.

\section{Conclusions}

The current seismic-resistant design method has been developed to allow for ductility of residential buildings to resist large earthquakes. While these buildings are designed to remain elastic in small or moderate earthquakes, they are allowed to experience plastic deformations in severe earthquakes to prevent the collapse and save human lives. This design approach has been effective in protecting people; however, it may not be sufficient for modern, complex societies. In past large earthquakes, many buildings that were damaged but did not collapse were resulting in vast human casualties.

Studying the concepts described above, we believe that there is still a room to improve the current seismic design practice. Most structural engineers understand the rationale behind a seismic design approach in which plastic deformation of beams, columns, and walls are anticipated; however, the shaking due to big earthquakes is equivalent to the casualties in human being and the building itself. Therefore, the limitation or allowable shaking level must be designed during big earthquakes.

\section{References}

1. Major Damage Earthquake Occurred in Japan, after 1996 (in Japanese), Japan Meteorology Agency. (http://www.data.jma.go.jp/svd/eqev/data/ higai/higai1996-new.html)

2. Seismic Intensity Level and Acceleration. Weather and Earthquakes, Seismic Intensity Information. 2003, Japan Meteorology Agency (http://www. jma.go.jp/en/quake/quake_sindo_index.html)

3. Wood, H.O. and Neumann, F., Modified Mercalli Intensity Scale of 1931, Seismological Society of America Bulletin, 21(4), 1931, pp. 277-283. 
Wariyatno, N.G. et al. / Proposed Design Philosophy for Seismic-Resistant Buildings / CED, Vol. 21, No. 1, March 2019, pp. 1-5

4. Grigoriu, M., 2016, Do Seismic Intensity Measures (IMs) Measure up?, Probabilistic Engineering Mechanics, 46, 80-93.
5. Verdugo, R, 2018, Seismic Site Classification, Soil Dynamics and Earthquake Engineering, In press, corrected proof, Available online November 2018. 